CAHIER 2697

\title{
NATURAL-RESOURCE EXPLOITATION WITH COSTLY ENFORCEMENT OF PROPERTY RIGHTS
}

\author{
Louis HOTTE
}

Centre de recherche et développement en économique (C.R.D.E.) and Département de sciences économiques, Université de Montréal

December 1997

Comments are appreciated. This work forms a part of the author's Ph.D. thesis in progress at the Université de Montréal. The author is most grateful to Professor Gérard Gaudet for his precious comments. This paper has also benefited from comments by Nancy Bergeron, Michel Poitevin, Stephen Salant, as well as by the participants at the Colloquium on Natural Resources and Environmental Economics, organized by CIRANO and GREEN (Universite Laval), 1997. This research was conducted partly under the auspices of the PARADI program which links the C.R.D.E., Université de Montréal, and CRÉFA, Université Laval, and which is financed as a Center of excellence in international development by the Canadian International Development Agency. The author takes sole responsibility for any remaining errors. 


\section{RÉSUMÉ}

Cette étude propose un modèle d'exploitation des ressources naturelles lorsque les droits de propriété sont onéreux à faire respecter. II y est démontré comment, sur un site de ressources naturelles, une hausse du produit moyen de la main-d'œuvre peut contribuer à faire augmenter les coûts d'exclusion d'empiéteurs potentiels; il ne serait donc pas optimal, pour le propriétaire du site, d'exploiter à un niveau tel que le produit marginal de la main-d'œuvre soit égal à son coût. II serait même admissible que le propriétaire engage de la main-d'œuvre dont le produit marginal soit négatif. Le niveau de salaire constitue un paramètre important de l'analyse. On trouve que lorsque le niveau de salaire de l'économie est déjà peu élevé, des réductions de salaire subséquentes peuvent contribuer à réduire les rentes découlant de l'exploitation du site. Et en deçà d'un certain seuil, des rentes positives deviennent inatteignables, forçant son propriétaire à abandonner le site; ce dernier devient alors soumis à un accès libre. L'analyse expliquerait le fait que les droits de propriété soient plus difficiles à faire observer dans les pays en voie de développement. De plus, elle suggère un cadre d'analyse à partir duquel certaines questions d'ordre normatif pourraient être abordées, telles que les bienfaits du commerce international avec coûts endogènes des droits de propriété, l'optimalité des décisions de définir les droits de propriété, l'effet de la distribution des revenus sur les coûts d'application des droits de propriété, etc.

Mots clés: droits de propriété, coûts d'exclusion, ressources naturelles, niveaux de revenus, économie du développement, économie du crime, travail illicite

\section{ABSTRACT}

This paper proposes a model of natural-resource exploitation when private ownership requires costly enforcement activities. For a given wage rate, it is shown how enforcement costs can increase with labor's average productivity on a resource site. As a result, it is never optimal for the site owner to produce at the point where marginal productivity equals the wage rate. It may even be optimal to exploit at a point exhibiting negative marginal returns. An important parameter in the analysis is the prevailing wage rate. When wages are low, further decreases in the wage rates can reduce the returns from resource exploitation. At sufficiently low wages, positive returns can be rendered impossible to achieve and the site is abandoned to a free-access exploitation. The analysis provides some clues as to why property rights may be more difficult to delineate in less developed countries. It proposes a different framework from which to address normative issues such as the desirability of free trade with endogenous enforcement costs, the optimality of private decisions to enforce property rights, the effect of income distribution on property rights enforceability, etc.

Key words : property rights, enforcement costs, natural resources, income levels, economic development, economics of crime, illegal labor 
Le premier qui ayant enclos un terrain, s'avisa de dire, Ceci est à moi, et trouva des gens assés simples pour le croire, fut le vrai fondateur de la société civile. Que de crimes, de guerres, de meurtres, que de miséres et d'horreurs, n'eût point épargnés au Genre-humain celui qui arrachant les pieux ou comblant le fossé, eût crié à ses semblables. Gardez-vous d'écouter cet imposteur; vous êtes perdus, si vous oubliez que les fruits sont à tous, et que la terre n'est à personne.

Jean Jaques Rousseau (1754), Discours sur l'origine et les fondements de l'inégalité parmi les hommes Quoy celui qui a planté, semé et enclos na pas droit au fruit de ses peines. Voltaire's reaction (175?), cited in Havens (1966)

\section{Introduction}

Ill-defined property rights are often cited as a major cause underlying the inefficient exploitation of natural resources. Although present in both industrialized and less developed countries, the problem seems to be more accute in the latter ${ }^{1}$. This begs the question not only as to why property rights may be deficient on some natural resource sites ${ }^{2}$, but also as to why it seems more difficult to protect those rights in less developed economies.

Observing that property rights are not as well defined in less developed countries, a few theoretical inquiries have considered the effects of trade between industrialized regions with well defined property rights and less industrialized regions with deficient property rights (see, e.g., Chichilnisky 1994; Brander and Taylor [1995, 1996]; Tornell and Velasco 1992). These studies take tenure regimes in both regions as exogenous to the analysis. In this respect, a more fundamental issue is being sidesteped which may affect some of their conclusions about the effects of trade: they do not account for the causes of the different prevailing tenure regimes.

Another branch of the literature on property rights offers various reasons explaining the different tenure regimes in effect accross regions or periods. Some authors contend that it may be

\footnotetext{
${ }^{1}$ World Bank (1992, Chapter 3).

${ }^{2}$ For the present purpose, the expression natural resource site is meant to apply mostly to renewable resources such as inshore fisheries, pasture lands, forests, irrigation systems, hunting territories, etc., evolving in a steady-state (see Gordon (1954) for instance). I therefore abstract from any dynamic considerations such as the nonrenewability of a resource or out of steady-state behavior.
} 
related to a society's culture, religion, legal institutions, etc. (North 1990; Cohen and Weitzman 1975; Firmin-Sellers 1995). Others have suggested that securing those rights be the result of a cost-benefit analysis on the part of the private owner. If there are costs associated with property enclosure, ownership will be claimed only as long as benefits from exploitation exceed enclosure costs. Anderson and Hill (1975) advocate such economic incentives underlying the determination of property rights. In their formulation, enclosure movements are mostly driven by exogenous technological progress in enforcement technology and by changes in output prices. Within the context of an open international economy, their analysis, however, can hardly account for the differences in property rights regimes observed between industrialized and less developed economies. Field's (1989) approach gets closer to providing an explanation by observing that an increase in population can lead to a reduction in exclusion costs through the increased supply of labor. Unfortunately, he does not provide us with a complete analytical framework. What is needed, therefore, is a theoretical framework which, based on economic incentives, provides clues as to why it seems more difficult to claim ownership over natural resource sites in less developed countries. The present study proposes one.

As mentioned above, one of the principal impediments for the delineation of property rights resides in the often too large costs of enforcement. An individual who holds a title to a resource site must decide whether to engage in costly enforcement activities in order to exclude potential encroachers. This analysis attempts to determine which factors may affect these costs.

Accepting that well defined property rights require the costly activity of excluding encroachers, one can assume that the higher the incentives to encroach, the costlier it is to exclude. My analysis borrows from the literature on the economics of crime and the supply of illegal labor in order to pin down an individual's incentives to encroach. This leads to the determination of an enforcement cost function for a resource site, according to which enforcement costs are positively related to the value of average product of labor on the site, but negatively related to the prevailing legal wage rate in the economy.

The proposed enforcement cost function enters the profit function of the holder of the title 
to a site. I show that under reasonable assumptions regarding the functional forms of both the production and detection functions, rents from a resource site exploitation may actually decrease following a reduction in the legal wage rate. Moreover, there exists a positive threshold level of the wage rate for which further reductions in its value make it prohibitively expensive to protect one's property from encroachment. This suggests a strictly economic rationale for the lack of well defined property rights observed in low income or pre-industrial economies, which differs from other oft-mentioned non-economic factors such as differences in technology, culture, legal institutions, etc. The model also allows us to verify Demsetz's (1967) conjecture which states that an increase in resource value is likely to lead to better delineated property rights.

The paper is organised as follows: Section 2 determines the general shape and arguments of an enforcement cost function for the definition of property rights on a natural resource site; partial equilibrium exploitation decisions for a profit maximizing resource site owner are then derived. The effects of varying the legal wage rate on the profit function are presented in Section 3. In Section 4, I consider the effects of increasing the resource price on the delineation of property rights. The conclusion presents a discussion of the results and proposes some extensions.

\section{The Model}

In this section, a model will be developed which leads to an enforcement cost function for the delineation of property rights over the exploitation of a resource site. In order for property rights over a resource site to be well defined, it must be the case that the holder of those rights, the owner, receive all the benefits from its exploitation and bear all the costs. These costs take the form of direct exploitation costs, but must also include the costs involved in enforcing property rights, i.e. ensuring that no one will encroach on the property. It must be emphasized that the fact that nobody encroaches on the property does not imply that enforcement activities are absent; to the contrary, it implies that these activities are important enough to completely discourage any desire to encroach. I do not exclude, however, the possibility of partially defined property rights, in 
which case the owner could consider that it is in her own best interest, given the costs of excluding encroachers, to let a certain amount of the site's output be captured by encroachers. We will see below, however, that in the proposed model, a profit maximizing site owner will never opt to partially define her property rights ${ }^{3}$; she either completely eliminates all incentives to encroach or, if enforcement costs are too large, she abandons the site to a free access exploitation. Note that in this last case, the institution of private property will not be sufficient to prevent free access from occuring in equilibrium. Moreover, private decisions to have well defined property rights may not be a socially efficient outcome as there are now costs involved in defining property rights ${ }^{4}$.

Consider now the following model of natural resource exploitation with costly enforcement of property rights. Assume a community inhabited by a total of $N$ workers and a certain number of owners, which may comprise natural resource site owners as well as any other type of productive capital ownership. All workers receive a legal wage from a job they hold in the official or legitimate sector, which includes employment by a resource site owner who hires workers and pays them the going wage rate. Workers must, however, allocate their spare time after official working hours, between leisure and illegal activities ${ }^{5}$. The latter takes the form of encroachment over a resource site. Workers are assumed to be consumers as well, thus facing a trade-off between consumption levels and leisure time.

Of interest to us is the behavior of the owner who holds a title to a resource site. In order to maximize returns from the site, she must decide on how many workers to hire at the going legal wage rate for the direct exploitation of the resource, and on how much enforcement activities to undertake in order to discourage encroachment. This includes relinquishing the site to a free access exploitation where no enforcement activities take place.

In order to concentrate on the problem faced by the owner of a site, let us consider a partial

\footnotetext{
${ }^{3}$ Instances of partial enforcement appear in Helsley and Strange (1994), Milliman (1986), Sutinen and Anderson (1985) and Clarke et al. (1993). Tietenberg (1996, p. 293) provides a short interpretation.

${ }^{4} \mathrm{On}$ the efficiency of private decisions to enforce property rights, see Anderson and Hill (1975), de Meza and Gould (1992), Lasserre (1994) and Field (1989).

${ }^{5}$ See Ehrlich (1973), p. 528, for a discussion of the choice between taking part in both legitimate and illegitimate activities or specializing in one type of activity.
} 
equilibrium setting in which both the wage rate and the resource price are exogenously determined. The owner and encroachers engage in a sequential game where the owner first chooses the amount of workers, $L$, to hire on the site and the amount of enforcement expenditures, $x$, devoted to containing encroachment. In making these choices, she anticipates the encroachers' reaction to them. As will be described below in more details, the amount of enforcement expenditures can reduce encroachment activities by increasing the probability of detecting an encroacher on the site, denoted by $\lambda(x)$. Each worker constitutes a potential encroacher and they all simultaneously choose the amount of time to spend encroaching, $h_{i}, i=1, \ldots, N$, after having observed $L$ and $x$. Note that the workers hired by the site owner are part of the $N$ encroachers but that encroachment activities can only occur after official working hours. All $N$ workers/encroachers are thus identical in that each receives a legal wage, $w$, prior to deciding on encroachment activities. Note also that due to the assumed large number of potential encroachers, it is considered prohibitively costly for the owner to contract with every single one of them.

Since the owner is the first mover, let us begin by first deriving the encroachers' reaction to the choices of $L$ and $x$.

\subsection{The decision to encroach}

Workers face a trade-off between consumption levels and leisure time. Borrowing from the literature on the supply of illegal or unofficial labor 6 , let us assume that a worker derives utility from both consumption of goods, $c$, and leisure time, $T \Leftrightarrow h$, where $T$ is the total amount of leisure time available after official working hours, and $h$ denotes time spent on illegal activities. The following simple representation of utility will be used $^{7}$ :

$$
U(c, h)=c(1 \Leftrightarrow h)
$$

\footnotetext{
${ }^{6}$ For a review and some references, see Cowell (1990, chapter 5).

${ }^{7}$ Schmidt and Witte (1984, Appendix 9.2) provide a good discussion of the assumptions on a utility function using leisure and consumption as its arguments.
} 
where $T$ has been normalized to one. Recall that all workers are assumed to be active within the official sector; the only choice variable resides in the amount of time, $0 \leq h \leq 1$, spent on illegal activities after legal working hours. The utility function implies that workers are risk-neutral as far as their consumption levels are concerned ${ }^{8}$ and that higher consumption levels increase the opportunity cost of leisure time.

The period of inelastically supplied legal work being normalized to one, legal work brings in a wage $w$ with certainty for that period. Illegal work, which takes the form of encroachment over a resource site, involves an element of uncertainty regarding its return. This is due to the fact that an encroacher, if detected, will be punished. For simplicity, I will assume that punishment carries a monetary value equivalent to a fine which confiscates all illegal income, and that the probability of being detected depends solely on the decision to encroach, regardless of the amount of time spent encroaching. Hence, if the probability of being detected is given by $\lambda(x)$, consumption will be equal to $c_{0}=w$ with probability $\lambda(x)$ and to $c_{1}=w+h w_{i l}$ with probability $1 \Leftrightarrow \lambda(x)$, where $w_{i l}$ represents the return from illegal activities ${ }^{9}$. It is natural to assume that $w_{i l}$ is equal to the value of average product $(V A P)$ of labor time on the site ${ }^{10}$. The encroachment problem proposed here is in many respects similar to the problem of free access exploitation developed in Dasgupta and Heal (1979), the main differences being that the opportunity cost of exploiting the resource for the encroacher is given by the value of his leisure time and that the encroacher must face a probability of being

\footnotetext{
${ }^{8}$ See Block and Heineke (1973) and Cowell (1981) on the supply of labor under income uncertainty.

${ }^{9}$ See Becker (1968), Ehrlich (1973), and Heineke (1978) for similar representations of an individual's decisions to participate in illegitimate activities when there is a probability of apprehension and punishment. In the present model, punishment takes the general form of a proportional fine, $f=\gamma h w_{i l}$, with $\gamma=1$ for simplicity. Any other factor of proportionality would preserve the essence of the results. Lump-sum and infinitely large fines are ruled out; they are believed to be either inefficient or socially unacceptable. See, for instance, Stigler (1970), Friedman and Sjostrom (1993) and Van Rijckeghem and Weder (1997) on the magnitudes of fines.

${ }^{10}$ Productivity differences due to investments or better technology by the owner are assumed away. See Besley (1995) for theory and evidence on property rights and investment incentives.
} 
fined if detected. The function $\lambda(x)$ will be assumed to satisfy the following properties ${ }^{11}$ :

$$
\lambda^{\prime}(x)>0, \lambda^{\prime \prime}(x)<0, \lambda(0)=0, \lim _{x \rightarrow \infty} \lambda(x)=1, \lim _{x \rightarrow \infty} \lambda^{\prime}(x)=0, x \geq 0 .
$$

Let $R(H)$ be the total output function for the resource site, where $H$ denotes the total amount of labor time exploiting the site, i.e. $H=L+\sum_{i=1}^{N} h_{i}$. Hence, $V A P=V A P(H)=p R(H) / H$, where $p$ is the resource price in units of consumption goods. I will assume that $V A P^{\prime}(H)<0$ and that there exists $0<\bar{H}<\infty$ such that $V A P(\bar{H})=0$. Having observed the choice of $L$ and $x$ by the owner of the site, the $j$ th encroacher will maximize his expected utility by choosing $h_{j}$, taking as given $h_{i}, i \neq j$, in order to solve the following problem:

$$
\max _{h_{j}} E[U]=(1 \Leftrightarrow \lambda(x))\left[w+h_{j} V A P\left(L+\sum_{i \neq j} h_{i}+h_{j}\right)\right]\left(1 \Leftrightarrow h_{j}\right)+\lambda(x) w\left(1 \Leftrightarrow h_{j}\right) .
$$

The equilibrium decisions of the encroachers must therefore satisfy, for an interior solution, the following set of first-order conditions for $j=1, \ldots, N$ :

$$
\left(1 \Leftrightarrow h_{j}^{*}\right)(1 \Leftrightarrow \lambda(x))\left[V A P(H)+h_{j}^{*} V A P^{\prime}(H)\right]=w+(1 \Leftrightarrow \lambda(x)) h_{j}^{*} V A P(H)
$$

The right-hand side of the above relation gives the loss in expected utility due to a marginal reduction in leisure time, i.e. it represents the opportunity cost of leisure time. The left-hand side represents the net gain in expected utility resulting from the change in income. In equilibrium, of course, the marginal gain must equal the marginal loss. Rearranging equation (4), we get ${ }^{12}$,

$$
(1 \Leftrightarrow \lambda(x))\left[\left(1 \Leftrightarrow 2 h_{j}^{*}\right) V A P(H)+\left(1 \Leftrightarrow h_{j}^{*}\right) h_{j}^{*} V A P^{\prime}(H)\right]=w
$$

\footnotetext{
${ }^{11}$ The analysis does not consider the issue of third party enforcement (North 1990, Chapter 7 ). Once an encroacher has been reported to the authorities by a site owner, he is automatically punished and the amount of the fine goes to the treasury.

${ }^{12}$ Note that the first-order conditions imply: $\partial h_{j}^{*} / \partial w<0, \partial h_{j}^{*} / \partial \lambda<0$ and, beyond a certain value of $N$, $\partial h_{j}^{*} / \partial L<0$. These comparative statics results are consistent with empirical investigations on income-generating illegal activities which state that (Heineke 1978): an increase in the probability of being detected, or in the going wage rate, reduces the individual supply of illegal labor; conversely, a larger return to illegal work, which in this case is equivalent to a reduction in $L$, has the opposite effect. See also Ehrlich (1973) on this.
} 
Note that since $V A P(H) \geq 0$ and $V A P^{\prime}(H)<0$, we must have $h_{j}^{*}<1 / 2$ in order for the first-order condition to hold. A symmetrical equilibrium, where $h_{i}^{*}=h^{*}$, for all $i=1, \ldots, N$, will satisfy:

$$
(1 \Leftrightarrow \lambda(x))\left[\left(1 \Leftrightarrow 2 h^{*}\right) V A P\left(L+N h^{*}\right)+\left(1 \Leftrightarrow h^{*}\right) h^{*} V A P^{\prime}\left(L+N h^{*}\right)\right]=w .
$$

Following Dasgupta and Heal (1979, p. 61), consider now the limiting case where $N$ tends to infinity. It can be verified from (6) that there exists a certain $\bar{N} \geq 1$ beyond which $h^{*}$ is monotone decreasing in $N^{13}$. Suppose then that $h^{*}$ were to tend to some strictly positive value as $N$ goes to infinity. This would mean that $N h^{*}$ becomes infinitely large and therefore $V A P\left(L+N h^{*}\right)=0$. The left-hand side of (6) would then be strictly negative and the first-order condition could not hold. As a result, it must be the case that as $N$ tends to infinity, $N h^{*}$ remains finite and $h^{*}$ goes to zero. The first-order condition is thus, for sufficiently large $N$ :

$$
(1 \Leftrightarrow \lambda(x)) V A P\left(L+N h^{*}\right)=w
$$

In other words, as $N$ becomes sufficiently large, $h^{*}$ becomes infinitesimally small, with the result that the opportunity cost of leisure time becomes simply equal to $w$ and the expected utility gain from a marginal increase in encroachment time becomes $(1 \Leftrightarrow \lambda(x)) V A P\left(L+N h^{*}\right)$. Note that the fact that $h^{*}$ is small does not imply that encroachment is not a significant problem for the owner. This is because $N$ is large so that $N h^{*}$ could be large. It should be noted also that the model replicates Gordon's (1954) result that for a free access resource, i.e. one where $\lambda(x)=0$ and $L=0$, we get $V A P\left(N h^{*}\right)=w$, i.e. taking into account the opportunity cost of labor, all rents from the site are exhausted when $N$ is sufficiently large ${ }^{14}$.

Equation (7) determines how much encroachment $N h^{*}$ will occur for any choice of $L$ and $x$ by the owner. It is the implicit reaction function of the encroachers that the site owner will take as given in making her decisions.

\footnotetext{
${ }^{13}$ It can also be verified that the symmetrical equilibrium is unique and stable. (Varian 1992, p. 287)

${ }^{14}$ The conditions that justify the assumption of period-by-period rent dissipation for a free access common property, as in Gordon (1954), are laid out in Brooks et al. (1996).
} 


\subsection{The decision to exploit and enforce a site}

The owner wishes to choose the amount of labor to employ, $L$, and the amount of enforcement activities or expenditures $^{15}, x$, in order to maximize profits,

$$
\max _{x, L} \Pi=V A P\left(L+N h^{*}\right) L \Leftrightarrow w L \Leftrightarrow x,
$$

where $N h^{*}$ is given implicitly by equation (7). The first-order conditions for this problem are:

$$
\begin{gathered}
\frac{\partial \Pi}{\partial L}=V A P\left(L+N h^{*}\right) \Leftrightarrow w+V A P^{\prime}\left(L+N h^{*}\right)\left(1+\frac{\partial\left(N h^{*}\right)}{\partial L}\right)=0, \\
\frac{\partial \Pi}{\partial x}=\Leftrightarrow 1+V A P^{\prime}\left(L+N h^{*}\right) \frac{\partial\left(N h^{*}\right)}{\partial x}=0 .
\end{gathered}
$$

Notice that since $h_{i}$ cannot be negative, $N h^{*}$ is bounded from below by zero. Hence, from (7), we get $\partial\left(N h^{*}\right) / \partial L=\Leftrightarrow 1$ when $N h^{*}>0$, and $\partial\left(N h^{*}\right) / \partial L=0$ when $N h^{*}=0$. But since positive profits imply that $V A P \Leftrightarrow w>0, \partial \Pi / \partial L$ is strictly positive when $N h^{*}>0$ and $\Pi>0$. As a result, for any given $x, L$ must be such that $N h^{*}=0$ in equilibrium. In other words, if $N h^{*}>0$ and profits are positive, profits can be increased by increasing $L$. Notice also that once $N h^{*}$ is equal to zero, further increases in $L$ cannot be offset by reductions in $N h^{*}$. Therefore, for given $x, V A P$ starts decreasing with increases in $L$ and we get $(1 \Leftrightarrow \lambda(x)) V A P(L)<w$, i.e. the expected utility gain from encroaching becomes strictly smaller than its cost. But this cannot be a profit maximizing equilibrium since $x$ could be reduced until the equality is reestablished, resulting in an increase in profits. Let us denote by $E$ the level of enforcement expenditures that minimizes enforcement costs, while respecting equation (7) with $N h^{*}=0$. Therefore, $E$ is given by $\lambda(E)=1 \Leftrightarrow w / V A P(L)$, or

\footnotetext{
${ }^{15}$ In practice, enforcement activities can take the form of direct supervision time by the owner, hired guards which may be paid a preferential wage in order to "buy" their honesty, and some material expenditures.
} 
implicitly by ${ }^{16}$

$$
E=E\left(1 \Leftrightarrow \frac{w}{V A P(L)}\right)
$$

with $E^{\prime}>0, E^{\prime \prime}>0, E=0$ when $w=V A P(L)$, and $\lim _{V A P \rightarrow \infty} E=\lim _{w \rightarrow 0} E=+\infty$. These properties for $E(\cdot)$ are derived from the properties of $\lambda(x)$ assumed in $(2)$.

Equation (11) defines the implicit relation that must prevail in equilibrium between enforcement expenditures, $E$, and the value of average product of labor, which itself depends on the quantity $L$ of labor hired on the site. This relation will be referred to as the enforcement cost function associated with a privately held natural resource site. This function can now be inserted into the profit function of the owner in order to analyse its impact on exploitation levels and private decisions to secure property rights. For an exogenous resource price, $p$, and wage rate, $w$, the profit derived by an owner from a site on which property rights are fully protected from encroachment are now:

$$
\Pi=p R(L) \Leftrightarrow w L \Leftrightarrow E,
$$

where $E=E(1 \Leftrightarrow w / V A P(L))$. Notice how the choice of labor not only affects the direct returns from exploitation, $p R(L) \Leftrightarrow w L$, but also indirectly affects enforcement costs through its effect on $V A P(L)$. Both values being dependent on the number of workers employed, $L$ constitutes the owner's sole choice variable.

The first-order condition for a profit maximizing interior solution is:

$$
R^{\prime}\left(L^{*}\right)=\frac{w}{p}\left[1+\frac{E^{\prime}(\cdot)}{V A P^{2}} \frac{\partial V A P}{\partial L}\right] .
$$

Since $\partial V A P / \partial L<0$, we have $p R^{\prime}\left(L^{*}\right)<w$. Hence the owner of the site employs labor at a level for which the value of marginal productivity is lower than the wage rate. Note that this result

\footnotetext{
${ }^{16}$ Note that the detection probability function used here implies that the available technology does not allow for perfectly enclosed properties. This is in line with Barzel's observation that "fences around orchards are not made to be totally insurmountable." (Barzel 1989, p. 110). But this does not necessarily imply that one cannot deter all theft, contrary to Barzel's assertion in the same paragraph. As the present model implies, if thieves are expected utility maximizing individuals, there will always exist a finite level of protection expenditures which will completely eliminate any incentives for theft.
} 
obtains despite the fact that all benefits and costs accrue to the owner of the resource, i.e. no encroachment occurs. Depending on the exact form of the production and enforcement functions, it could even be optimal, given the wage rate and the resource price, for the owner of a site to employ labor with negative marginal productivity.

In order to simplify the analysis and illustrate the results, let us assume a quadratic production function $^{17}$, i.e. $R(L)=(A \Leftrightarrow B L) L$, with $A, B>0$. Then $\partial V A P / \partial L=\Leftrightarrow p B$ and equation (13) becomes:

$$
R^{\prime}\left(L^{*}\right)=\frac{w}{p}\left[1 \Leftrightarrow p B \frac{E^{\prime}(\cdot)}{V A P^{2}}\right]
$$

This result is presented in Figure 1, where subscripts 1 and 2 refer to different enforcement and production functions, thus illustrating two possible cases of resource exploitation. $L_{F}$ refers to the level of exploitation of a free access resource, in which all rents are exhausted, i.e. average product equals the wage rate ${ }^{18}$.

The intuition behind the above result is as follows: At the point where the value of labor's marginal productivity equals the wage rate, adding a worker to the exploitation of the resource increases revenues by the same amount as its direct cost, the wage rate. Enforcement expenditures, however, can be reduced since the now lower average productivity makes encroachment less attractive. Therefore, it pays to hire that extra worker. Each further addition to the labor force will yield less than the wage rate and this, at an increasing rate, as there are decreasing returns to labor; conversely, if the gains in reduced enforcement costs occur at a constant or diminishing rate, then an

\footnotetext{
${ }^{17}$ Such a functional form is quite common in the study of renewable resources; de Meza and Gould (1992) explicitely use such a form. Brander and Taylor (1995) implicitely use such a function for a steady-state harvest. Using their notation, it is straightforward to derive their steady-state harvest function as $H^{S S}\left(L_{H}\right)=(\alpha K) L_{H}-\left(\alpha^{2} K / r\right) L_{H}^{2}$, where $K$ denotes the "carrying capacity" of the resource, $r$ is the "uncongested" growth rate, and $\alpha$ represents a harvest efficiency coefficient.

${ }^{18}$ See Gordon (1954) for an early technical analysis on the exploitation of open access natural resources, Hardin (1968) for an intuitive approach on the "Tragedy of the Commons" or Baumol and Oates (1988, pp. 26-28) for a concise presentation. As mentioned by Ostrom (1990), this theory abstracts from the fact that individuals may organize to improve the efficiency of exploitation of a resource subject to free access. Once a site becomes exploited by an organized group, it can no longer be referred to as free access property but rather as common property. But then this group must devote resources to enforce its exploitation rules and exclude others. In this respect, the site has effectively become enclosed and can be treated as a privately owned site. See also Barzel (1989, p. 71) on this.
} 


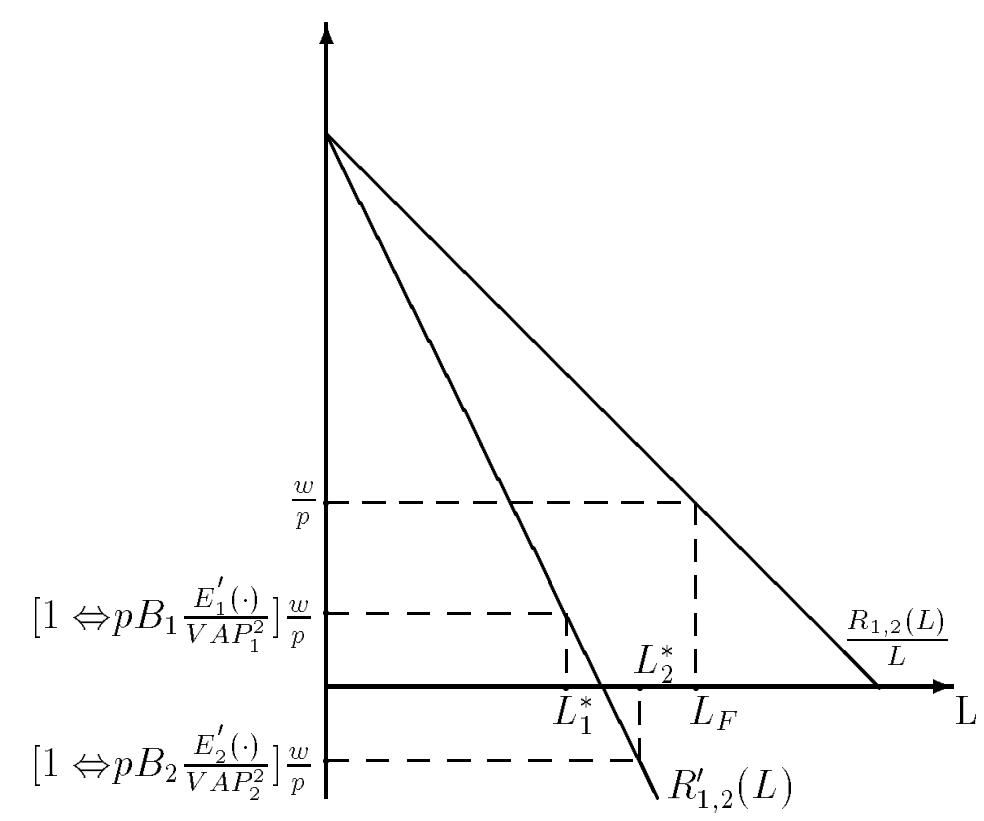

Figure 1: Enforcement costs and equilibrium exploitation of a privately owned resource site

employer will hire more workers until the two effects exactly offset each other. An interior solution for $L^{*}$ will exist whenever the marginal gain in reduced enforcement costs equals the marginal loss of increased production at a level below $L_{F}$. If the marginal enforcement gain and production loss curves do not meet before $L_{F}$ is reached, then it will never be optimal for an individual to claim ownership over the resource. Note that the existence of an interior solution is not sufficient for the resource site to be privatized; an additional condition is that profits be positive at that point.

We therefore observe that if enforcement costs are positively related to a resource site's value of average productivity of labor, then the level of exploitation will exceed that for which the value of marginal productivity equals the wage rate, even though no encroachment occurs on the site. It is interesting to note that in their study of range land exploitation on Southwestern Indian reservations in the United States, Johnson and Libecap (1980) have observed the use of overgrazing as a means of discouraging potential entrants. They attribute this suboptimal situation to the authorities' refusal to grant formal recognition of land ownership to large herders. The emphasis is thus put on the role of a third party, i.e. the authorities. The foregoing analysis suggests that one should also consider the role played by private decisions to enforce and by incentives to encroach from other individuals on the reservation. Note also that the effectiveness of detection activities could depend on the choice of commodities produced by the owner. This is instanced by Cheung (1970) with the 
observation that in Tripolitania, more valuable almond production was replaced by cattle raising because almond trees were more difficult to police than cattle which can be driven home at night. In the detection function given by Equation 15 below, almond trees would have a higher $\theta$ than cattle.

\section{The Effect of the Wage Rate on the Equilibrium Outcome}

The foregoing analysis allows us to perform some comparative static experiments in order to determine the role played by relevant parameters such as an economy's prevailing wage rate or resource price. In order to perform comparative static experiments, let us assume that the function $\lambda(x)$ takes the following form:

$$
\lambda(x)=1 \Leftrightarrow e^{-x / \theta}
$$

where $\theta$ is a shift parameter. It is easy to verify that this function has the required properties. Substituting $\lambda(x)=\lambda(E)=1 \Leftrightarrow w / V A P(L)$ and inverting the function, we find that:

$$
E=\theta \ln \left(\frac{V A P(L)}{w}\right)
$$

The profit function can now be expressed as follows:

$$
\Pi(L ; A, B, \theta, p, w)=p(A \Leftrightarrow B L) L \Leftrightarrow w L \Leftrightarrow \theta \ln \left(\frac{p(A \Leftrightarrow B L)}{w}\right) .
$$

Maximizing with respect to $L$ yields the following first-order conditions for an interior solution:

$$
\frac{\partial \Pi}{\partial L}=p\left(A \Leftrightarrow 2 B L^{*}\right) \Leftrightarrow w+\frac{\theta B}{A \Leftrightarrow B L^{*}}=0
$$

In Appendix A, it is shown that the equilibrium amount of labor is:

$$
L^{*}=\frac{1}{4 p B}\left[(3 p A \Leftrightarrow w) \Leftrightarrow \sqrt{(3 p A \Leftrightarrow w)^{2} \Leftrightarrow 8 p[\theta B+A(p A \Leftrightarrow w)]}\right] .
$$

Equations (17) and (18) allow us to study the effect of $w$ on equilibrium profits. The analysis suggests that a reduction in the prevailing wage rate of an economy will have two opposite effects 
on profit levels: the standard one is to increase profits by reducing the wage bill paid to workers; the other is to reduce profits by indirectly increasing enforcement costs. As shown below, which effect prevails may depend upon the wage level.

Taking the derivative of profits with respect to $w$ at $L^{*}$, we have:

$$
\frac{\partial \Pi^{*}}{\partial w}=\Leftrightarrow L^{*}+\frac{\theta}{w}
$$

Therefore, on the one hand, a marginal reduction in the wage rate pushes up profits by $L^{*}$ through a reduction in labor costs; on the other hand, profits are brought down by $\theta / w$ through larger enforcement costs due to increased incentives to encroach for poorer workers. Note that if $\theta=0$, so that $\lambda=1$, thus eliminating the need for enforcement expenditures, we recover Hotelling's lemma by removing the right hand side's second term. With the help of Equation (20), the general shape of the profit function, $\Pi^{*}$, with respect to the wage rate is derived in Appendix $B$ and illustrated by Figure 2. The curve labelled $\Pi_{N E}^{*}$ depicts standard equilibrium profits as a function of $w$ when enforcement costs are nonexistent, i.e. $\theta=0$.

The largest equilibrium rents occur at $\bar{w}=2 \theta B / A$. At $w_{H}=(1 / 2)(p A+\sqrt{p A(p A \Leftrightarrow 2 \bar{w})})$, we have $\Pi^{*}=0$ and $\partial \Pi^{*} / \partial w=0$. The wage rate is then so high that gross returns from exploitation are just enough to cover enforcement costs. Further increases in the wage rate make it impossible to cover enforcement costs and all incentives to establish property rights vanish. Notice that $\bar{w}<$ $w_{H}<p A$. As the wage goes down from $w_{H}$, equilibrium profits first behave in the usual way, i.e. they are convex and decreasing with $w$. At high wages, the direct effect on gross returns from exploitation outweigh the effect on enforcement costs. But as $w$ is further reduced, the function becomes concave. It reaches a slope of zero at $\bar{w}$. At that point, the enforcement effect overtakes the direct exploitation effect and additional reductions in wages reduce profit levels. At wages below $w_{L}$, legal incomes are so low that workers' willingness to encroach make enforcement costs prohibitive. The site is left to open access exploitation. It is shown in Appendix $\mathrm{B}$ that $w_{L}$ is strictly positive ${ }^{19}$.

\footnotetext{
${ }^{19}$ Note that the sign of the second derivative of $\Pi^{*}(w)$ between 0 and $\bar{w}$ has not been determined. For the present
} 


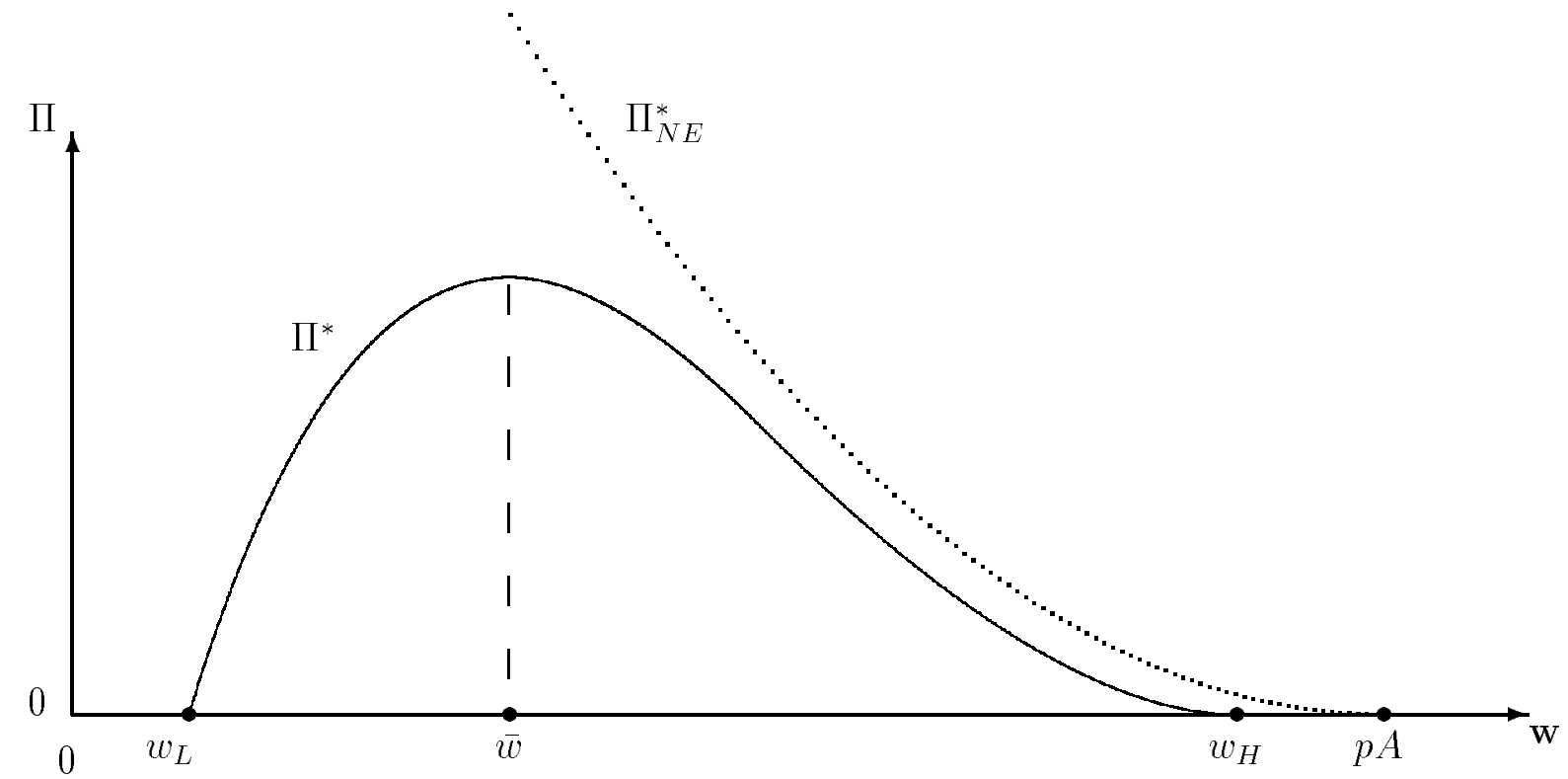

Figure 2: Profits as a function of wage

Note that there are discontinuities at $w_{L}$ and $w_{H}$. At wages below $w_{L}$ and above $w_{H}$, negative returns could always be dealt with by employing just enough workers to make the value of average productivity equal to the wage rate. By (16), this drives enforcement costs to zero. But profits are also equal to zero. This is essentially equivalent to open access exploitation.

These results regarding the possible behavior of equilibrium profits as the wage rate varies carry interesting implications for the study of property rights determination and natural resource exploitation in less developed countries or in the economic history of industrialized countries. It provides an economic rationale for the lack of well-defined property rights in those economies as compared to industrialized countries. Figure 2 suggests that for a less developed country with comparatively low wages, incentives to enclose natural resource properties tend to be weak. For higher wages closer to $\bar{w}$, incentives to enclose properties are more important. It must be stressed that these conclusions do not rest on any exogenous institutional or cultural differences. Given purpose, the important point to make is that within the interval, both the first derivative and $w_{L}$ are strictly positive. 
individuals' latent threat to encroach, economic agents may be making the most efficient decision by leaving access to some resources open to all. Any added profit resulting from a reduced level of exploitation would be exceeded by larger enforcement costs at $w \leq w_{L}$. In this case, distributing titles to hitherto free access natural resource sites as a means of reducing the intensity of exploitation would result in wasted energies as the new owners would find no economic incentives to actually protect the sites from encroachment.

\section{The Effects of an Increase in Resource Value on the De- lineation of Property Rights}

In this section, I propose to verify, within the present context, Demsetz's (1967) conjecture which holds that an increase in the value of a resource is likely to lead, ceteris paribus, to a better delineation of property rights. Demsetz illustrates his point by mentioning a study of the Montagnais Indians in Québec which "established the fact that a close relationship existed, both historically and geographically, between the development of private rights in land and the development of the commercial fur trade." (Demsetz 1967, p. 351). Surmising that the advent of the fur trade resulted in an increase in the value of furs, the study supports his conjecture. Nevertheless, in his Economic analysis of property rights, Barzel (1989) points out that Demsetz's conjecture may not always hold. He does recognize that on the one hand, an increase in the value of a resource leads to a higher return from delineation. But on the other hand, incentives for theft are also made higher, thus increasing the costs of policing. There is no a priori reason to believe that the first effect will prevail

over the second one. As shown below, the present model indicates that within a partial equilibrium framework, an increase in the value of a resource cannot lead to less well delineated property rights. I present the proof of this assertion here because it provides us with some insight.

Suppose that at some initial price $p_{0}$ and wage rate $w$, an owner maximizes her profits by choosing to employ $L_{0}$ workers. Assuming positive profits, this site is operated under private ownership. I will now demonstrate that, ceteris paribus, an increase in the resource price cannot lead to a reduction 
in equilibrium profits from private ownership; hence, it cannot lead to the abandonment of a site to free access.

Let the price of the resource increase to $p_{1}>p_{0}$, with a constant wage rate. Although it may not be her profit maximizing choice, the owner could then always choose to employ $L_{1}$ workers in order to satisfy $V A P_{1}\left(L_{1}\right)=V A P_{0}\left(L_{0}\right)$, i.e. such that enforcement costs remain the same. Inserting this into the profit function (17), we get the following inequality:

$$
\left[V A P_{0}\left(L_{0}\right) \Leftrightarrow w\right] L_{0} \Leftrightarrow \theta \ln \left(\frac{V A P_{0}\left(L_{0}\right)}{w}\right)<\left[V A P_{1}\left(L_{1}\right) \Leftrightarrow w\right] L_{1} \Leftrightarrow \theta \ln \left(\frac{V A P_{1}\left(L_{1}\right)}{w}\right)
$$

since $p_{1} R\left(L_{1}\right) / L_{1}=p_{0} R\left(L_{0}\right) / L_{0}$ implies $L_{1}>L_{0}$ when $p_{1}>p_{0}$, and $V A P_{0}>w$ if initial profits are to be positive. This completes the demonstration that equilibrium profits cannot decrease following an increase in resource price.

The intuition behind the above result is that even though the value of the resource has increased, the owner could always keep enforcement costs the same by reducing the attractiveness of the resource through an adjustment in the average productivity of labor. In effect, it is as if the new price structure allowed the owner to replicate the old one by resorting to some form of "destruction of value". ${ }^{20}$ The point is that the initial relative values remain an option at the new higher prices, but the reverse is not true.

\section{Conclusion}

In his seminal paper on property rights, Steven Cheung posed the following question: "Why do exclusive rights not exist for certain actions? Because of the legal institutions, or because policing

\footnotetext{
${ }^{20}$ I surmise that a similar reasoning would apply to the case presented in Barzel (1989, p. 67). Barzel points out that in a theater with bad and good tickets, it is not possible to say if a doubling in the value of all tickets will lead to a better delineation in prices. He argues that on the one hand, "the difference in valuation between a bad and a good seat would double, too, and therefore the return from pricing the difference would increase... however, the costs of policing would also increase, ... [since] people would gain more from stealing the difference, by buying tickets from the low-priced seats, for instance, and then attempting to occupy the higher priced ones." (Barzel 1989, p. 67). What the present model suggests is that the theater's managers could always replicate the previous price differences either by reducing the relative value of the better seats (making them less comfortable) or by reducing the value of all seats (hiring less famous actors).
} 
costs are prohibitive?" (Cheung 1970, p. 58) The role played by the first part of the answer, legal institutions, is now well recognized. The English enclosure movement of the eighteenth century, attributed mostly to a parliamentary statute which substantially reduced the fixed costs associated with enclosure, is a well known case (McCloskey 1975). By contrast, similar attempts at privatizing the commons in Old Regime France met little success due to high litigation costs which are attributed to the lack of support from a central authority (Rosenthal 1992). But in this paper, the set of legal institutions was assumed constant in order to consider the second part of the answer to Cheung's question i.e., the role played by policing costs. To this end, I proposed a framework from which to address the problem of natural resource exploitation when private ownership calls for costly enforcement activities.

Enforcement costs were endogenized by explicitely describing individuals' incentives to encroach on a resource site. It was shown that the equilibrium level of exploitation chosen by the owner exceeds that for which the value of marginal product of labor equals the wage rate. This is so, even though no encroachment occurs in equilibrium. At first sight, it may thus seem that the owner of a site overexploits her resources. However, when the endogenous enforcement costs are accounted for, it becomes clear that this is not the case. The intuition is that an owner has two ways of discouraging encroachers: she can either raise the probability of detection with larger enforcement expenditures, or she can reduce the returns from encroaching by increasing the intensity of exploitation, thus lowering labor's value of average product on the site. In equilibrium, the owner will use a combination of both.

It was also shown that for reasonable functional forms, reductions in the wage rate may actually result in lower equilibrium profits. This is explained by the fact that when the legal wage rate of an economy is already quite low, further reductions so severely foster incentives to encroach that increased enforcement costs outpace any additional direct profit from exploitation. Moreover, there exists a threshold level of the legal wage rate below which positive profits become impossible to achieve, with the result that the site is left to free access. Although these results were obtained with specific functional forms, they did not require unreasonable assumptions about utility, detection, 
or production functions.

Considering that wages are usually lower in less developed economies, the analysis provides a formalized explanation as to why their property rights on natural resource sites are not so well delineated as in industrialized economies. In some circumstances, the delineation of property rights may be viewed as a response of agents to endogenous economic variables rather than a response to different institutions. In this respect, some policy prescriptions that foster private ownership in less developed countries in order to replicate their industrialized counterparts may end up being more costly than beneficial. Moreover, the distribution of a title to a previously unclaimed resource site may not prevent it from being exploited as a free access resource.

Allowing tenure arrangements to depend on the wage rate brings up the following question: Is a better delineation of property rights a prerequisite to economic growth or is it the other way around? The foregoing analysis suggests that they go hand in hand. Economic growth, when associated with an increase in wages, will reduce the pressure from encroachers and thus lead to a better delineation of property rights. The ensuing gain in efficiency in the exploitation of natural resources should promote growth further. How this works out exactly will require a general equilibrium analysis and goes beyond the scope of this study.

A second line of research which is suggested by the above analysis has to do with the distribution of wealth. It was assumed, all along, that workers' income originated solely from their work wages. There may be a case, here, for a Pareto improvement resulting from a better distribution of property ownership between site owners and workers. By claiming a share of the rents from resource sites, workers' income will increase, thereby reducing enforcement costs for the exploitation of the sites. For the owners, the gains from reductions in enforcement costs may outweigh the foresaken shares of the rents. ${ }^{21}$

\footnotetext{
${ }^{21}$ An interesting study which tends to support this beneficial effect resulting from a better distribution of wealth is that of Johnsen (1986). The author argues that the Southern Kwakiutl Amerindians of the Canadian West Coast, whose wealth dependent mostly on salmon, made use of a custom called the Potlatch system as a way to reduce incentives for members of one group to encroach upon another's salmon fishery. The Potlatch consisted of a ceremony where gifts of significant value were exchanged, thus amounting to a redistribution of income. A Potlatch host gained social status proportional to his generosity. As the author notes, the system could only function because salmon
} 
Another aspect which has been eschewed is the optimality of private decisions to enclose resource sites and the optimal amount of government support. One would think that the government could make it easier for owners to exclude encroachers, but at what cost? What is the nature of the government's intervention? Is it a substitute or a complement to an owner's enforcement activities?

Finally, the model proposes a framework from which to study the effects of international trade on natural resource exploitation, assuming that tenure arrangements are endogenously determined. The model could be adapted to study the effects of international trade on the environment in a similar framework.

being fished in rivers, the territories were relatively easy to protect from encroachment; this was not the case for Amerindians of the interior who dependent mostly on buffalo and antelope, which dwelt over large open areas. 


\section{APPENDIX}

\section{A The determination of $L^{*}$}

In the first part of this appendix, it is shown that $L^{*}$ is a local maximum. It is subsequently shown that $L^{*}$ is also a global maximum.

If we multiply through the first-order condition (18) by $A \Leftrightarrow B L^{*}$ and rearrange, we get the second degree polynomial:

$$
2 p B^{2} L^{* 2} \Leftrightarrow B(3 p A \Leftrightarrow w) L^{*}+[\theta B+A(p A \Leftrightarrow w)]=0 .
$$

Its roots are given by

$$
L_{1,2}^{*}=\frac{1}{4 p B}\left[(3 p A \Leftrightarrow w) \pm \sqrt{(3 p A \Leftrightarrow w)^{2} \Leftrightarrow 8 p[\theta B+A(p A \Leftrightarrow w)]}\right]
$$

where $L_{1}^{*}$ and $L_{2}^{*}$ respectively denote the smallest and largest roots. The condition for a real value of $L^{*}$ is:

$$
(3 p A \Leftrightarrow w)^{2} \geq 8 p[\theta B+A(p A \Leftrightarrow w)]
$$

Note that the R.H.S. of this inequality must be positive since it is assumed that $w \leq p A$; otherwise positive profits would be impossible to achieve, even in the absence of enforcement costs. Rearranging the inequality, we get: $(p A+w)^{2} \geq 8 p \theta B$. We will assume throughout that $(p A)^{2}>8 p \theta B$, i.e.

$$
p A>8 \frac{\theta B}{A}
$$

In order for $L_{1}^{*}$ to be a local maximum, it is necessary to show that the second derivative of the profit function is negative at $L_{1}^{*}$. The direct way to do this is to insert the value of $L_{1}^{*}$ into the second derivative of $\Pi(L)$, and verify its sign. But since this leads to a very complex expression, we will proceed indirectly as follows.

We know that $\Pi(L)$ and $\Pi^{\prime}(L)$ are continuous and finite over the interval $0 \leq L<A / B$. Therefore, since $L_{1,2}^{*}>0$ because $\sqrt{(3 p A \Leftrightarrow w)^{2} \Leftrightarrow 8 p[\theta B+A(p A \Leftrightarrow w)]}<3 p A \Leftrightarrow w$, the slope of the profit function changes sign at most twice for $L>0$. From Equations (19) and (23), we note that $0<L_{1}^{*}<(3 p A \Leftrightarrow w) / 4 p B<L_{2}^{*}$. As a result, it suffices to show, for the second derivative to be negative at $L_{1}^{*}$, that $[\partial \Pi / \partial L]_{L=0}>0$ and $[\partial \Pi / \partial L]_{L=(3 p . A-w) / 4 p B}<0$. The first expression is

$$
\left.\frac{\partial \Pi}{\partial L}\right|_{L=0}=p A \Leftrightarrow w+\frac{\theta B}{A},
$$


which is positive since $p A>w$. The second expression is

$$
\left.\frac{\partial \Pi}{\partial L}\right|_{L=\frac{3 p A-w}{4 p B}}=p\left[A \Leftrightarrow 2 B\left(\frac{3 p A \Leftrightarrow w}{4 p B}\right)\right] \Leftrightarrow w+\frac{\theta B}{A \Leftrightarrow B\left(\frac{3 p A-w}{4 p B}\right)} .
$$

The R.H.S. will be negative if assumption (25) holds. This completes the proof that $L^{*}$ is a local maximum.

In order to show that $L^{*}$ is also a global maximum, let us proceed with a proof by contradiction.

Suppose that there exists an $L^{\prime}$ such that $\Pi\left(L^{\prime}\right)>\Pi\left(L_{1}^{*}\right)$. Since $\partial \Pi / \partial L>0$ for $0<L<L_{1}^{*}$, we must have $L^{\prime}>L_{1}^{*}$.

Choose $L_{0}$ such that $V A P\left(L_{0}\right)=w$. We have $\Pi\left(L_{0}\right)=0$ since both enforcement costs and profits are zero. If $\Pi\left(L_{1}^{*}\right)>0$, we must have $L_{0}>L_{1}^{*}$, since $V A P\left(L_{1}^{*}\right)>w$ and $\partial V A P / \partial L<0$.

For $L>L_{1}^{*}, \Pi^{\prime}(L)$ can change sign only once at $L_{2}^{*}$. Combining this with the fact that at $\Pi\left(L_{0}\right)=0$, we have $L_{0}>L_{1}^{*}$, we get $L^{\prime}>L_{0}$. But then $V A P\left(L^{\prime}\right)<w$, implying $\Pi\left(L^{\prime}\right)<0<\Pi\left(L_{1}^{*}\right)$. A contradiction. This completes the proof that $\Pi\left(L_{1}^{*}\right)$ is a global maximum.

\section{B Equilibrium profits and wage levels}

This appendix describes how the curve relating equilibrium profits on a resource site to the prevailing wage rate has been derived. Its construction will proceed in four parts. These four parts provide sufficient information to draw $\Pi^{*}(w)$ as illustrated in Figure 2. Together, parts 1, 2 and 4 explain the portion of curve $\Pi^{*}(w)$ between $\bar{w}$ and $w_{H}$. Parts 1 and 3 explain the portion between 0 and $\bar{w}$. Part 5 is used to show that $\Pi^{*}(w)$ is continuous and smooth between $w_{L}$ and $w_{H}$.

1. At $\bar{w}=2 \theta B / A$, we have $\partial \Pi^{*}(\bar{w}) / \partial w=0, \Pi^{*}(\bar{w})>0$ and $\partial^{2} \Pi^{*}(\bar{w}) / \partial w^{2}<0$.

2. There exists $w_{H}, \bar{w}<w_{H}<p A$, such that $\Pi^{*}\left(w_{H}\right)=0$ and $\partial \Pi^{*}\left(w_{H}\right) / \partial w=0$.

3. $\partial \Pi^{*} / \partial w>0$ for $w \in(0, \bar{w})$ and $\lim _{w \rightarrow 0} \Pi^{*}=\Leftrightarrow \infty$. This implies the existence of $w_{L} \in(0, \bar{w})$ such that $\Pi^{*}\left(w_{L}\right)=0$.

4. $\partial \Pi^{*} / \partial w<0$ for $w \in\left(\bar{w}, w_{H}\right)$.

5. $\Pi^{*}(w)$ is continuous and smooth between $w_{L}$ and $w_{H}$.

\section{B.1}

$\left.\frac{\partial \Pi^{*}}{\partial w}\right|_{\bar{w}}=0$ 
Proof: From (20), we have $\partial \Pi^{*} / \partial w=0 \Leftrightarrow L^{*}=\theta / w$. Let $w=\bar{w} \equiv 2 \theta B / A$ and insert into (19) to get $L^{*}=A / 2 B=\theta / \bar{w}$. QED

$$
\left.\frac{\partial^{2} \Pi^{*}}{\partial w^{2}}\right|_{\bar{w}}<0
$$

Proof: From (20), we have

$$
\frac{\partial^{2} \Pi^{*}}{\partial w^{2}}=\Leftrightarrow \frac{\partial L^{*}}{\partial w} \Leftrightarrow \frac{\theta}{w^{2}} .
$$

Multiplying Equation (18) through by $A \Leftrightarrow B L^{*}$, we get the implicit derivative:

$$
\frac{\partial L^{*}}{\partial w}=\frac{A \Leftrightarrow B L^{*}}{B\left(4 p B L^{*}\right)\left[L^{*} \Leftrightarrow \frac{3 p A-w}{4 p B}\right]} .
$$

Using the fact that at $\bar{w}=2 \theta B / A$ we have $L^{*}=A / 2 B$, we get:

$$
\left.\frac{\partial^{2} \Pi^{*}}{\partial w^{2}}\right|_{\bar{w}}=\frac{L^{*}}{p A \Leftrightarrow \bar{w}} \Leftrightarrow \frac{L^{*}}{\bar{w}} .
$$

Therefore, $\partial^{2} \Pi^{*} / \partial w^{2}<0$ at $\bar{w}$ iff $p A>2 \bar{w}=4 \theta B / A$, which we have assumed to hold at (25). QED

$\Pi^{*}(\bar{w})>0$

Proof: Inserting $\bar{w}=2 \theta B / A$ and $L^{*}=A / 2 B$ into the profit function (17), we get:

$$
\Pi^{*}(\bar{w})=\frac{p A}{4 B / A} \Leftrightarrow \theta\left[1+\ln \left(\frac{p A}{4 \theta B / A}\right)\right] .
$$

This implies

$$
\Pi^{*}(\bar{w})>0 \Leftrightarrow \frac{p A}{2 \bar{w}}>1+\ln \left(\frac{p A}{2 \bar{w}}\right) .
$$

This last inequality holds for $p A>8 \theta B / A$. QED 


\section{B.2}

$\Pi^{*}\left(w_{H}\right)=0$, for $w_{H} \in[\bar{w}, p A)$

Proof: We will show that at $w_{H}$, we have $V A P\left(L_{H}^{*}\right)=w_{H}$; this implies zero enforcement costs and zero profits.

If $V A P\left(L_{H}^{*}\right)=w_{H}$, then $L_{H}^{*}=\left(p A \Leftrightarrow w_{H}\right) / p B$. Substituting into the first-order condition (18), we get

$$
w_{H}^{2} \Leftrightarrow p A w_{H}+p B \theta=0
$$

or equivalently, $w_{H 1,2}=\left[p A \pm \sqrt{p^{2} A^{2} \Leftrightarrow 4 p B \theta}\right] / 2$. In order for $L_{H}^{*}$ to be a maximum at $w_{H}$, Equation (19) indicates that we need $L_{H}^{*}=\left(p A \Leftrightarrow w_{H}\right) / p B<\left(3 p A \Leftrightarrow w_{H}\right) / 4 p B$, or equivalently, $w_{H}>p A / 3$. Since we have assumed that $p A>8 \theta B / A$, this implies

$$
\bar{w}<w_{H}=\frac{p A+\sqrt{(p A)^{2} \Leftrightarrow 4 p \theta B}}{2}<p A
$$

$L_{H}^{*}$ satisfies the profit maximizing first-order condition at $w_{H}<p A$ and $V A P\left(L_{H}^{*}\right)=w_{H}$. QED

$\frac{\partial \Pi^{*}\left(w_{H}\right)}{\partial w}=0$

Proof: Substitute $L_{H}^{*}=\left(p A \Leftrightarrow w_{H}\right) / p B$ into Equation (20) to get $\partial \Pi^{*}\left(w_{H}\right) / \partial w=\Leftrightarrow(p A \Leftrightarrow$ $\left.w_{H}\right) / p B+\theta / w_{H}$. Suppose that $\partial \Pi^{*}\left(w_{H}\right) / \partial w \neq 0$. Then, from the previous equation, we get $w_{H}^{2} \Leftrightarrow p A w_{H}+p B \theta \neq 0$. This contradicts Equation (30). QED

\section{B.3}

$\left.\frac{\partial \Pi^{*}}{\partial w}\right|_{0<w<\bar{w}}>0$

Proof: From Equation (20), we have $\partial \Pi^{*} / \partial w>0 \Leftrightarrow L^{*}<\theta / w$. Substituting into Equation (19) and rearranging, this implies:

$$
\underbrace{w(3 p A \Leftrightarrow w) \Leftrightarrow 4 p \theta B}_{F(w)}<\underbrace{w \sqrt{(3 p A \Leftrightarrow w)^{2} \Leftrightarrow 8 p[\theta B+A(p A \Leftrightarrow w)]}}_{G(w)}
$$


We need to show that $G(w)>F(w)$ for $w \in(0, \bar{w})$. First, we note that $G(w)>0$ for $w>0$. $F(w)$ is a polynomial of degree two with $F^{\prime}(w)=3 p A \Leftrightarrow 2 w>0$ for $w<p A$. Its roots are $w_{1,2}=\left[3 p A \pm \sqrt{9(p A)^{2} \Leftrightarrow 16 p \theta B}\right] / 2$. Since we have assumed that $p A>8 \theta B / A$, it is easy to show that $w_{1} \in(0, \bar{w})$ and $w_{2}>w_{H}$. Since $\bar{w}<p A$, this implies $F(w) \leq 0$ for $w \leq w_{1}=$ $\left[3 p A \Leftrightarrow \sqrt{9(p A)^{2} \Leftrightarrow 16 p \theta B}\right] / 2$. Therefore, $F(w)<G(w)$ for $w \leq w_{1}$.

It remains to show that $F(w)<G(w)$ for $w \in\left(w_{1}, \bar{w}\right)$. Within that range, $F(w) \geq 0$, hence $F(w)<G(w) \Rightarrow F^{2}(w)<G^{2}(w)$, i.e.

$$
G^{2}(w) \Leftrightarrow F^{2}(w)=A w^{3} \Leftrightarrow\left(2 \theta B+p A^{2}\right) w^{2}+3 p A \theta B w \Leftrightarrow 2 p(\theta B)^{2} \equiv H(w)>0 .
$$

Suppose that $H(w) \leq 0$ for some $w \in\left(w_{1}, \bar{w}\right)$. Since $H\left(w_{1}\right)>0$ and $H(\bar{w})=0$, this implies that there exists $w^{*} \in\left(w_{1}, \bar{w}\right)$ such that $H\left(w^{*}\right)=0$. Moreover, since $H(w)$ is a polynomial of degree three, $H^{\prime}(w)$ has at most two zeros. Therefore, $H\left(w^{*}\right)=H(\bar{w})=H\left(w_{H}\right)=0$ where $w^{*}<\bar{w}<w_{H}$ implies that $H^{\prime}(\bar{w})>0$. Taking the derivative of $H(w)$, substituting $\bar{w}=2 \theta B / A$ and rearranging, this implies $H^{\prime}(\bar{w})=4(\theta B)^{2} / A \Leftrightarrow p A \theta B>0$, or $p A<4 \theta B / A$. This violates the assumption that $p A>8 \theta B / A$. Therefore, $H(w)>0$ for $w \in\left(w_{1}, \bar{w}\right)$. QED

$\lim _{w \rightarrow 0} \Pi^{*}(w)=\Leftrightarrow \infty$

Proof: Equilibrium profits can be expressed as:

$$
\Pi^{*}(w)=\left[V A P\left(L^{*}\right) \Leftrightarrow w\right] L^{*} \Leftrightarrow \theta \ln \frac{V A P\left(L^{*}\right)}{w},
$$

where the first term on the R.H.S. of the equality represents direct exploitation profits while the second term represents enforcement costs. From Equation (19), we have $\lim _{w \rightarrow 0} L^{*}=[3 p A \Leftrightarrow$ $\left.\sqrt{(p A)^{2} \Leftrightarrow 8 p \theta B}\right] / 4 p B<A / B$. Therefore, $0<\lim _{w \rightarrow 0} V A P\left(L^{*}\right)<+\infty$. This implies $\lim _{w \rightarrow 0} V A P\left(L^{*}\right) / w=+\infty$. Inserting these results into the the equilibrium profit function, we get finite direct exploitation profits but infinitely large enforcement costs as $w$ approaches zero. QED

\section{B. 4}

$\left.\frac{\partial \Pi^{*}}{\partial w}\right|_{\bar{w}<w<w_{H}}<0$

Proof: We need to show that $L^{*}>\theta / w$ for $w \in\left(\bar{w}, w_{H}\right)$. Let us borrow from the expressions defined in Equations (31) and (32). It was shown that $F(w)>0$ for $w \in\left(\bar{w}, w_{H}\right)$. Therefore, $H(w)<0 \Leftrightarrow L^{*}>\theta / w$ for $w \in\left(\bar{w}, w_{H}\right)$. 
Suppose that $H(w)>0$ for some $w^{\prime} \in\left(\bar{w}, w_{H}\right)$. Since $H^{\prime}(w)$ has at most two zeros, and $H(w)>0$ for $w \in(0, \bar{w})$ and $H^{\prime}(\bar{w})<0$, then $H^{\prime}\left(w_{H}\right)<0$. But $H^{\prime}\left(w_{H}\right)=(A / 2)(p A \Leftrightarrow 4 \theta B / A)[p A+$ $\left.\sqrt{(p A)^{2} \Leftrightarrow 4 p \theta B}\right]>0$ since $p A>8 \theta B / A$ by assumption. A contradiction. Therefore, $H(w)<0$ for $w \in\left(\bar{w}, w_{H}\right)$. QED

\section{B.5}

Demonstration that $\Pi^{*}(w)$ is continous and smooth over the interval $\left(0, w_{H}\right]$ :

From $(19), L^{*}(w)$ is continous and finite for $w \in\left(0, w_{H}\right]$. This implies that $\operatorname{VAP}\left(L^{*}(w)\right)=$ $p\left(A \Leftrightarrow B L^{*}(w)\right)$ is continous and finite over the interval $\left(0, w_{H}\right]$. Hence, $\Pi^{*}\left(L^{*}(w), w\right)$ is continous over $\left(0, w_{H}\right]$. From $(29)$, we have $\partial L^{*} / \partial w<0$. Since $\lim _{w \rightarrow 0} L^{*}<A / B, \partial \Pi^{*} / \partial w$, as defined by $(20)$, is continous and finite over $\left(0, w_{H}\right]$. This completes the demonstration. 


\section{References}

Anderson, Terry L. and P. J. Hill, "The Evolution of Property Rights: A Study of the American West," The Journal of Law and Economics, April 1975, 18, 163-179.

Barzel, Yoram, Economic Analysis of Property Rights Political Economy of Institutions and Decisions, Cambridge, England: Cambridge University Press, 1989.

Baumol, William J. and Wallace E. Oates, The theory of environmental policy, Cambridge, England: Cambridge University Press, 1988.

Becker, Gary S., "Crime and Punishment: An Economic Approach," Journal of Political Economy, March-April 1968, \%6, 169-217.

Besley, Timothy, "Property Rights and Investments Incentives: Theory and Evidence from Ghana," Journal of Political Economy, 1995, 103 (5), 903-937.

Block, M. K. and J. M. Heineke, "The Allocation of Effort under Uncertainty: The Case of Risk-averse Behavior," Journal of Political Economy, 1973, 81, 376-385.

Brander, James A. and M. Scott Taylor, "International Trade and Open Access Renewable Resources: The Small Open Economy Case," NBER Working Paper Series 5021, National Bureau of Economic Research February 1995.

_ and _ _ "International Trade between Consumer and Conservationist Countries," Working Paper, University of British Columbia November 1996.

Brooks, R., J. Controneo, M. Murray, and S. Salant, "When is the Standard Analysis of Common Property Extraction under Free Access Correct? A Game-Theoretic Justification for 
Non Game-Theoretic Analyses," 1996. Mimeo, University of Michigan.

Cheung, Steven N. S., "The Structure of a Contract and the Theory of a Non-Exclusive Resource," Journal of Law and Economics, 1970, XIII, 45-70.

Chichilnisky, Graciela, "North-South Trade and the Global Environment," The American Economic Review, September 1994, 84 (4), 851-874.

Clarke, Harry R., William J. Reed, and Ram M. Shrestha, "Optimal enforcement of property rights on developing country forests subject to illegal logging," Resource and Energy Economics, 1993, 15, 271-293.

Cohen, Jon S. and Martin L. Weitzman, "A Marxian Model of Enclosures," Journal of Development Economics, 1975, 1, 287-336.

Cowell, F. A., "Taxation and Labour Supply with Risky Activities," Economica, November $1981,48,365-379$.

Cowell, Frank A., Cheating the Government: The Economics of Evasion, Cambridge, Massachusetts: The MIT Press, 1990.

Dasgupta, P. S. and G. M. Heal, Economic Theory and Exhaustible Resources, Welwyn, England: James Nisbet and Co. Ltd and Cambridge University Press, 1979.

de Meza, David and J.R. Gould, "The Social Efficiency of Private Decisions to Enforce Property Rights," Journal of Political Economy, 1992, 100 (3), 561-580.

Demsetz, Harold, "Toward a Theory of Property Rights," American Economic Review, 1967, $5 \%, 347-359$ 
Ehrlich, Isaac, "Participation in Illegitimate Activities: A Theoretical and Empirical Investigation," Journal of Political Economy, 1973, 81, 521-565.

Field, Barry C., “The Evolution of Property Rights," KYKLOS, 1989, 倓 (3), 319-345.

Firmin-Sellers, Kathryn, “The Politics of Property Rights," American Political Science Review, December 1995, 89 (4), 867-881.

Friedman, David and William Sjostrom, "Hanged for a Sheep - The Economics of Marginal Deterrence," Journal of Legal Studies, June 1993, XXII, 345-366.

Gordon, H. Scott, "The economic theory of a common-property resource: The fishery," Journal of Political Economy, April 1954, VXII, 124-142.

Hardin, Garrett, "The Tragedy of the Commons," Science, December 1968, 162, 1243-1248.

Havens, George R., Voltaire's Marginalia on the Pages of Rousseau: A Comparative Study of Ideas, New-York: Haskell House, 1966.

Heineke, J. M., "Substitution among Crimes and the Question of Deterrence: An Indirect Utility Function Approach to the Supply of Legal and Illegal Activity," in J. M. Heineke, ed., Economic Models of Criminal Behavior, North-Holland Publishing Company, 1978, chapter 5, pp. $153-209$.

Helsley, Robert W. and William C. Strange, "Exclusion and the private enforcement of property rights," Journal of Public Economics, 1994, 53, 291-308.

Johnsen, D. Bruce, "The Formation and Protection of Property Rights Among the Southern Kwakiutl Indians," Journal of Legal Studies, January 1986, XV, 41-67. 
Johnson, R.N. and G.D. Libecap, "Agency Costs and the Assignment of Property Rights: The Case of Southwestern Indian Reservations," Southern Economic Journal, October 1980, 47 (2), 332-347.

Lasserre, Pierre, "Protection décentralisée des droits de propriété, police et justice," L'Actualité économique, Revue d'analyse économique, juin 1994, 70 (2), 177-189.

McCloskey, Donald N., "The Economics of Enclosure: A Market Analysis," in William N. Parker and Eric L. Jones, eds., European Peasants and Their Markets: Essays in Agrarian Economic History, Princeton, New Jersey: Princeton University Press, 1975, pp. 123-160.

Milliman, Scott R., "Optimal Fishery Management in the Presence of Illegal Activity," Journal of Environmental Economics and Management, 1986, 13, 363-381.

North, Douglass C., Institutions, Institutional Change and Economic Performance The Political Economy of Institutions and Decisions, Cambridge, England: Cambridge University Press, 1990.

Ostrom, Elinor, Governing the Commons: The evolution of institutions for collective action The Political Economy of Institutions and Decisions, Cambridge, England: Cambridge University Press, 1990.

Rijckeghem, Caroline Van and Beatrice Weder, "Corruption and the Rate of Temptation: Do Low Wages in the Civil Service Cause Corruption?," IMF Working Paper WP/97/73, International Monetary Fund June 1997.

Rosenthal, Jean-Laurent, The Fruits of Revolution: Property Rights, litigation, and French Agriculture, 1700-1860 The Political Economy of Institutions and Decisions, Cambridge, 
England: Cambridge University Press, 1995.

Rousseau, Jean Jaques, Discours sur l'origine et les fondements de l'inégalité parmi les hommes, Gallimard, 1969.

Schmidt, Peter and Ann D. Witte, An Economic Analysis of Crime and Justice: Theory, Methods, and Applications, Academic Press, Inc., 1984.

Stigler, George J., “The Optimum Enforcement of Laws," Journal of Political Economy, 1970, $78,526-536$.

Sutinen, Jon G. and Peter Anderson, "The Economics of Fisheries Law Enforcement," Land Economics, November 1985, 61 (4), 387-397.

Tietenberg, Thomas H., Environmental and Natural Resource Economics, New-York: HarperCollins College Publishers, 1996.

Tornell, Aarón and Andrés Velasco, "The Tragedy of the Commons and Economic Growth: Why Does Capital Flow from Poor to Rich Countries?," Journal of Political Economy, 1992, $100(6), 1208-1231$.

Varian, Hal R., Microeconomic analysis, third ed., W. W. Norton and Company, 1992.

World Bank, World Development Report: Development and the Environment, Oxford: Oxford University Press, 1992. 